Scientific study of Reading, 1998, 2(1), 3:29

\title{
Phonological Mediation and Semantic and Orthographic Factors in Silent Reading in French
}

\author{
Liliane Sprenger-Charolles \\ Department of General and Applied Linguistics \\ CNRS-Leaple \& Université René Descartes
}

\author{
Linda S. Siegel \\ Department of Applied Psychology \\ Ontario Institute for Studies in Education
}

Danielle Béchennec

Institut National de Recherche Pédagogique et CNRS-Leaple, Paris

Liliane Sprenger-Charolles, CNRS/Université René Descartes, Department of General and Applied Linguistics, 12 rue Cujas, 75230 Paris CEDEX 05, France. Linda S. Siegel, Department of Applied Psychology, Ontario Institute for Studies in Education, 252 Bloor Street West, Toronto, Ontario, Canada M5S 1V6.

Acknowledgment: This research was partially supported by a grant from the National Institute for Studies in Education, Paris, France to L. Sprenger-Charolles and by a grant from the Natural Sciences and Engineering Research Council of Canada to L.S. Siegel. We would like to thank Eric Beltrando for designing the computer system for the reading tests.

Running Head: Phonological Mediation 


\begin{abstract}
The objectives of this series of three studies were to evaluate, first, whether French-speaking children mainly use phonological mediation in the first stage of reading acquisition in a silent reading task and, second, to examine the role of phonological processing in the construction of the orthographic lexicon. Forty-eight French children were followed from kindergarten to the end of second grade. Their phonological skills were assessed using a semantic categorization task with homophone and visual foils (first study); their orthographic skills were assessed by a choice task between a correct exemplar, a homophone, and a visual foil (second study). In the semantic categorization task the differences between the visual and homophone foils increased with time as the homophone foils were more and more likely to be chosen. In the orthographic choice task, performance improved with time, but errors were more likely to involve homophone foils. The results obtained by two subgroups of children who differed in their level of orthographic expertise at the end of second grade (third study) indicated that, one year earlier (at the end of first grade) the future "expert" spellers were more likely to use phonological processing in silent reading (semantic categorization task) than the future "poor" spellers. Moreover, in first grade, future spelling experts had better phonological skills in reading aloud and in spelling from dictation (pseudoword tasks) than the future poor spellers and they also had better phonological awareness skills at the beginning of the last year of kindergarten. These results suggest that French-speaking children use phonological mediation in silent reading tasks and that phonological processing contributes to the construction of the orthographic lexicon.
\end{abstract}


This series of studies of reading acquisition by French speaking children had two objectives. The first one was to evaluate whether French-speaking children mainly use phonological mediation in the first stage of reading acquisition in a silent reading task, as is the case in reading aloud (SprengerCharolles \& Casalis, 1995; Sprenger-Charolles, Siegel \& Béchennec, 1997; Sprenger-Charolles, Siegel $\&$ Bonnet, in press). The second one was to examine the role of phonological processing in the construction of the orthographic lexicon (see Share, 1995).

Two types of models are currently used to provide a framework for understanding the development of reading skills. The first type of models, derived from the dual route models (e.g., Humphreys \& Evett, 1985; Paap \& Noel, 1991), are stage developmental models (Frith, 1986; Harris \& M. Coltheart, 1986; Morton, 1989; Seymour, 1986). The other class of models has attempted to simulate reading acquisition with connectionist networks (see Seidenberg \& McClelland, 1989 and Seidenberg, Plaut, Peterson, McClelland \& McCrae, 1994 for a parallel distributed processing approach -- PDP -- and M. Coltheart, Curtis, Atkins \& Haller, 1993, for a dual route connectionist model). In our studies, we assessed phonological and orthographic skills of French children in the context of developmental stage type of models. We chose this type of models as the basis for our hypotheses because the connectionist approach has not produced, at least for the moment, a widely recognized set of arguments for reading acquisition. This is not the case for the developmental models derived from dual route models.

Dual route models of word recognition distinguish, for mature readers, two types of processing, i.e., a phonological procedure, also called indirect route, and a procedure of direct orthographic access, called direct route. The direct route is used mainly for high frequency words while the indirect route is used for low frequency words and pseudowords (M. Coltheart et al., 1993; Humphreys \& Evett, 1985; Paap \& Noel, 1991). These dual route models have been adapted to the acquisition of reading by Frith (1986) and Morton (1989; see also Harris \& M. Coltheart, 1986; Seymour, 1986). A feature of these developmental models is that they postulate that children use the indirect route in which all items, pseudowords and words of either high or low frequency are processed by phonological mediation ${ }^{1}$, before processing words by the direct orthographic route.

To assess these developmental changes in reading, lexical and non lexical factors are typically manipulated in reading aloud or in silent reading tasks. In reading aloud tasks, the use of the indirect phonological route is usually evaluated by the manipulation of a non-lexical factor, spelling to sound regularity. The production of regularization errors in the reading of irregular words is also considered as an indicator of the use of this pathway. Alternatively, lexical factors such as frequency and lexicality are considered as indicators of the use of the direct orthographic route.

The evidence from studies in which these types of factors are used clearly indicates that children primilarly use phonological processing at the beginning of reading acquisition. For example, in cross sectional studies with English-speaking children, a significant regularity effect was observed in younger as compared to older readers (see Backman, Bruck, Hebert \& Seidenberg, 1984; Seidenberg, Waters, Barnes \& Tanenhaus, 1984; Waters, Seidenberg \& Bruck, 1984). The younger children gave fewer correct responses, with longer latencies, for irregular words than for regular words of either high or low frequency. The same type of result was obtained for accuracy in studies with French children (see Leybaert \& Content, 1995; Sprenger-Charolles \& Casalis, 1995; Sprenger-Charolles, Siegel \& Béchennec, 1997). For example, in a longitudinal study with French first graders we observed a strong regularity effect after 5 months of reading instruction without clear evidence of orthographic processing, as we found no significant frequency and lexicality effects (Sprenger-Charolles, Siegel \& Béchennec, 1997). This regularity effect appeared to operate in the same way with French second graders, independent of the type of reading instruction that they received (Leybaert \& Content, 1995). 
A developmental change in reading processing was also observed in these studies. In the studies with English children, it was observed that in older children -- as in mature readers -- the difference between regular and irregular words existed only for low frequency words (Backman et al., 1984; Seidenberg et al., 1984; Waters et al., 1984). Similarly, our longitudinal data showed that children's performance at the end of first grade, unlike in the middle of the same year, was influenced by frequency and lexicality factors (Sprenger-Charolles, Siegel \& Béchennec, 1997). Nevertheless, we also obtained evidence for the use of phonological processing later in reading acquisition. A regularity effect, even greater than the one observed in the preceding session, was obtained at the end of first grade; similarly, the errors usually attributed to phonological processing (regularizations errors) increased with time.

Those results were obtained in tasks involving oral reading. This type of task allows a detailed analysis of errors; however, results may be biased by the fact that subjects are required to give an oral response (see Stanovich and Siegel, 1994). Therefore, it is important to use tasks that test whether or not children use phonological mediation in silent reading.

The most prevalent paradigm used in the last decade to assess silent reading was the semantic categorization task developed by Van Orden (1987). Subjects are required to say if items are exemplars of a specific semantic category, for example, is "roze" a flower? In this type of task, the effect of homophony between the correct exemplar ("rose") and either a homophone word (e.g., the foil "rows") or a homophone nonword (e.g., the foil "roze") is considered as an indicator of phonological processing.

For adults, the results indicated a homophony effect, which did not appear to vary with the lexical status of the foils, but which was less pronounced under certain circumstances; e.g., when the orthographic overlap between the correct exemplar and the foil was low (rose/rows, see Van Orden, 1987 and, for a non significant difference, Jared \& Seidenberg, 1991). Similarly, this effect appeared to be less marked for high frequency words, especially when narrow categories were used (Jared \& Seidenberg, 1991). Moreover, when the subject was asked to pay attention to the fact that there might be homophone items in the list, the homophone effect decreased (V. Coltheart, Patterson \& Leahy, 1994). This effect also appears to be less significant in good, as compared to poor adult readers (Lewellen, Goldinger, Pisoni \& Greene, 1993).

The paradigm most employed to assess the use of phonological procedures in the silent reading of children is somewhat different; foils are generally inserted in sentences that contain an inappropriate homophone word, or a homophone pseudoword. These sentences, therefore, sound right but look wrong (e.g., "She blue up the balloon", "I have noe time"). Doctor and M. Coltheart (1980) used this paradigm in a cross sectional study in which they compared the performance of 6 to 10 year old children. It was found that younger children (aged 6 to 8 years) accepted these two types of sentences in the majority of cases. These results, as Doctor and M. Coltheart have argued, are consistent with the hypothesis that young children use the indirect phonological route. As the phonological effect may be due to visual similarities between the homophone pseudoword and the correct word, a control for visual similarity was included in a subsequent experiment (Doctor \& M. Coltheart, 1980). In that study, the sentences that sounded correct produced more errors than the sentences that sounded incorrect but appeared visually more similar to the right ones. The pattern of results was somewhat different for older children (aged 9 to 10 years). They had a higher error rate on sentences with a homophone word as compared to sentences with a homophone pseudoword. The difference between word and pseudoword in the older group of children was attributed by Doctor and Coltheart to the fact that those children, unlike the younger ones, are able to use a direct route. However, in that experiment, most of the homophone words were regular and, therefore, could be read either by the direct orthographic route 
or by the indirect phonological procedure. Thus, it was not clearly demonstrated that older children use different processing than younger children.

To clarify whether children used the direct or the indirect phonological route, V. Coltheart, Laxon, Rickard and Elton (1988) utilized the same paradigm as Doctor and M. Coltheart (1980). To provide more conclusive evidence for the use of the direct route, they added irregular homophone words that cannot entirely be read by phonological mediation (e.g. "He through out the rubbish"). In order to examine the use of the other pathway, the indirect phonological route, they also utilized nonword homophones closely matched in visual similarities to control nonwords ("Her bloo dress was new" versus "The sky was bloa today"). V. Coltheart et al.'s study (1988) included adults as well as children. For our purpose, we will discuss only the results of the 5 groups of children: two groups of poor readers, 9 and 11 year old, and three groups of good readers, 8, 9 and 11 year old. It should be noted that those children were older than the two younger groups in the Doctor and M. Coltheart's study. Contrary to the results obtained by Doctor and M. Coltheart (1980), in the Coltheart et al.'s study (1988) a homophone effect with nonwords was observed in all children. This effect indicates, as V. Coltheart et al. (1988) argue, that all children, whatever their age or their reading level, use the indirect phonological route. The failure of Doctor and M. Coltheart's study to find such an effect with older children may therefore be due, as it was argued by V. Coltheart et al. (1988), to a ceiling effect obtained with the older children in sentences with a homophone nonword. V. Coltheart et al. (1988) have also observed that it was more difficult, for all children, to reject sentences containing an inappropriate irregular homophone. This result supports the suggestion that children are able to use, not only the indirect route, but also the direct orthographic route.

These results were partially replicated in a subsequent study by Johnston, Thompson, FletcherFlinn and Holligan (1995) with 8 and 11 year old children who had learned to read with either a phonic or with a non phonic method. In this study, as in Coltheart et al.'s (1988), homophone words and nonwords, as well as visual control items, were used. The only difference between the two studies was that Johnston et al. found no difference between sentences with a homophone nonword and those with visual control nonword in the 11 year-olds not taught with phonics. According to the authors, this result was due to ceiling effects.

It should be noted that Johnston et al. (1995) conducted a control experiment to verify that the results could not be attributed to a lack of knowledge of homophone meaning and spelling (see also Coltheart et al., 1988; Doctor \& Coltheart, 1980; Treiman, Freyd \& Baron, 1983).

All these studies indicated that children appear to use an indirect phonological procedure first, in the very beginning of reading acquisition, both in reading aloud and in silent reading (for reading aloud tasks in English, Backman et al., 1984; Seidenberg et al., 1984; Waters et al., 1984 and in French, Leybaert \& Content, 1995; Sprenger-Charolles \& Casalis, 1995; Sprenger-Charolles, Siegel \& Béchennec, 1997; for silent reading tasks, Doctor \& Coltheart, 1980). The results also indicated that this procedure is partially -- but not totally -- replaced, in a subsequent stage of reading acquisition, by a more direct orthographic procedure (for reading aloud tasks in English, Backman et al., 1984; Seidenberg et al., 1984; Waters et al., 1984 and in French, Sprenger-Charolles \& Casalis, 1995; Sprenger-Charolles, Siegel \& Béchennec, 1997; for silent reading tasks, V. Coltheart et al., 1988; Doctor \& Coltheart, 1980; Johnston et al., 1995). Nevertheless, since most of those studies were crosssectional (Backman et al., 1984; V. Coltheart et al., 1988; Doctor \& Coltheart, 1980; Johnston et al., 1995; Seidenberg et al., 1984; Waters et al., 1984), they do not allow assessment of the developmental process that might permit the child to construct his/her orthographic lexicon.

Recent longitudinal data have shown that phonological mediation is a mechanism that might allow the construction of the orthographic lexicon (See Share, 1995, for a review). This hypothesis is supported by the fact that substantial correlations were found between early pseudoword reading (which 
is the most common measure of phonological recoding) and later irregular word reading (e.g., Freebody \& Byrne, 1988; Byrne, Freebody \& Gates, 1992; Gough \& Walsh, 1991; Stanovich \& West, 1989). In a longitudinal study, Jorm, Share, MacLean and Matthews (1984) have also found evidence of a relationship between early phonological recoding skills and later reading skills. In this study, children in kindergarten were separated in two groups, decoders and non-decoders, according to their phonological recoding skills as measured by pseudoword reading. These two groups were followed for two years. The results indicated that the early good decoders were the children who had improved most in reading. At the end of the study, they were nine months ahead (in reading level) in a word reading test. Additional evidence of the role of phonological mediation was provided by Freebody and Byrne (1988) and Byrne et al. (1992) with a comparison between "Chinese" and "Phoenician" readers. The first group was characterized by a large reliance on the direct route and the second by the use of phonological mediation. The findings of Freebody and Byrne (1988) and Byrne et al. (1992) showed that the scores obtained by Phoenician readers improved between sessions -- including for irregular words -- while a deterioration in word reading skills was observed for the "Chinese" readers.

The role of phonological mediation in establishing an orthographic lexicon was also apparent in our longitudinal study of French first graders (Sprenger-Charolles, Siegel \& Béchennec, 1997). Early phonological skills, as evaluated by pseudoword or regular word reading, were predictive of later performance for irregular words; the converse, i.e., significant correlations between early irregular word reading and later performance on regular words and on pseudowords, was not observed. It is to be noted that these results were obtained both in reading and in spelling. In addition, in both modalities, the correlations between correct responses and regularization errors in the early stage of acquisition were positive and significant. These results are consistent with those obtained in other studies (Byrne et al., 1992; Gough \& Walsh, 1991; Jorm et al., 1984).

All the studies we have examined seem to present four main limitations. 1. Most of them are cross-sectional; therefore, they do not directly assess the development of reading processes (Backman et al., 1984; V. Coltheart et al., 1988; Doctor \& Coltheart, 1980; Johnston et al., 1995; Seidenberg et al., 1984; Waters et al., 1984). 2. In the majority of the longitudinal studies, the variables that would allow assessment of the different types of reading processing were not systematically manipulated (Byrne et al., 1992; Freebody \& Byrne, 1988; Gough \& Walsh, 1991). 3. All those studies use either reading aloud tasks (for English, see, Backman et al., 1984; Seidenberg et al., 1984; Waters et al., 1984 and, for French, see Leybaert \& Content, 1995; Sprenger-Charolles \& Casalis, 1995; Sprenger-Charolles, Siegel \& Béchennec, 1997), or silent reading tasks (V. Coltheart et al., 1988; Doctor \& Coltheart, 1980; Johnston et al., 1995) but have never used, to our knowledge, these two types of tasks simultaneously. 4. These studies have mostly been conducted in English. The results obtained by children learning to read in a language whose orthography is much more transparent than that of English, namely German, did not show the same trends (see Wimmer \& Hummer, 1990; Wimmer \& Goswami, 1994). For example, when the performance of German-speaking children was directly compared to those of English-speaking children (Wimmer \& Goswami, 1994), it was observed that the younger German children made fewer pseudoword errors than the older English children. The youngest English children's errors were mainly word substitutions and non responses while the youngest German children mainly produced neologisms. Moreover, high correlations between word and pseudoword reading times were found in the youngest German group $(\underline{r}=.93)$ but not in the youngest English group $(\underline{r}=.58)$. These results indicated that German children, unlike the English ones, used a phonological procedure from the very beginning of learning to read. Therefore, some of the conclusions of the developmental models may be biased because research has mainly been conducted in English, which is known to have deep relations between graphemes and phonemes. 
The present series of studies was designed to avoid some of the limitations of the previous ones. They are an extension of the study in which we assessed the development of reading procedures with reading aloud and spelling tasks with the same children (Sprenger-Charolles, Siegel \& Béchennec, 1997; see also Sprenger-Charolles, Siegel \& Bonnet, in press). Our aim was, first, to characterize as accurately as possible the type of processing used by French beginning readers (indirect phonological route and direct orthographic route) and, second, to examine the role phonological mediation plays in the construction of the orthographic lexicon. In the present studies, as opposed to the previous one, we used silent reading tasks.

To achieve our objectives, we followed a group of children for three years, from the last year of kindergarten to the end of second grade. In a first study (semantic categorization task) we examined whether or not the children primarily used phonological mediation in a silent reading task. For this purpose, we developed a semantic categorization task, using the Van Orden (1987) protocol (see above). This task included as experimental items, two types of pseudoword foils: homophone and visual control foils. Our predictions were that, if beginning readers use phonological mediation, we should systematically observe more errors for homophone foils than for visual foils even though the types of alternatives we had chosen usually lead to a reduction of this effect in mature readers (use of narrow categories and use of pseudowords constructed from high frequency words: see above, V. Coltheart et al., 1994; Jared \& Seidenberg, 1991). We also developed a control experiment (second study) in order to verify that the results of the semantic categorization task could not be attributed to a lack of knowledge of the homophone spellings. This second study was also used as an evaluation of the orthographic skills of the children. In a third study, we evaluated the relationships between phonological and orthographic skills by comparing two subgroups of children, a subgroup of "experts" in spelling and a subgroup of children who were "poor" in spelling at the end of second grade. Specifically, we examined: (a) the development, from first to second grade, of performance of these two subgroups of children on the semantic categorization task, (b) their early phonological skills as assessed by pseudoword reading/spelling in first grade, (c) the differences between those two subgroups in kindergarten (before reading acquisition) in phonological awareness tasks, (d) non verbal IQ and oral vocabulary at the same time to verify if the difference in "spelling expertise" is not due to differences at these two levels.

\section{STUDY 1}

To evaluate the use of phonological mediation in silent reading, we chose a variation of the semantic categorization task developed by Van Orden (1987). Subjects were required to say if items are exemplars of a specific semantic category, for example, "is pome (homophone foil) or pomne (visual foil) fruit"? (both are foils for the word pomme, [apple]). Our hypothesis was that, if children use primarily phonological mediation at the beginning of reading acquisition, we should observe that the homophone foils lead to more errors than the visual foils.

\section{Method}

\section{$\underline{\text { Subjects }}$}

We selected a group of more than 100 kindergartners who spoke French as their native language and who had no language or psychological difficulties and no motor problems, according to their teachers or school psychologists. We then selected the 60 children who were of average or above average cognitive functioning (fiftieth centile or higher on the Raven Progressive Matrices) and who 
were non-readers at the end of kindergarten. Reading level was evaluated by the BAT-ELEM reading test (Savigny, 1974).

From this sample, it was possible to follow 48 children until the end of second grade. For the first reading session (January of first grade) the mean age of children was 78.3 months ( $\underline{\mathrm{sd}} 3.21$ ). The children attended 20 different classes in 9 different schools in various areas in the suburbs of Paris. They came from a sample of different socio-economic levels. The teachers all used different "mixed" methods for reading instruction, with variations in regard to when grapheme-phoneme correspondence rules were explicitly taught.

\section{$\underline{\text { Stimuli, task and procedure }}$}

For the semantic category task, we used categories such as colors, animals, food, rather than broad abstract categories that are less accessible to young children. In order to be able to manipulate the relevant variables, we used only pseudowords as foils and only two different types of foils, homophone foils and visual foils. These two types of pseudowords were derived from high frequency regular words which have a spelling more likely to be known by young children than that of high frequency irregular words. For example, for the category food, the homophone foil, "pome", and the visual foil, "pomne", were used, both derived from the word pomme [apple]. The visual foils were not homophones of the exemplars but visually more similar to them than the homophone foils. Specifically, the visual foils had the same number of letters as the correct exemplars, and differed only by one letter; the letter replacement was visually similar to the correct one; for example, for the word auto [car], "o" instead of "a" (outo), for the word loup [wolf], "q" instead of "p" (louq), for the word pomme [apple], "n" instead of "m" (pomne). The homophone foils had, at least, one letter more or less than the exemplar ${ }^{2}$; for example, "oto" instead of auto or "pome" for pomme. The shape of the words used to construct the foils was, therefore, less well preserved in the case of the phonological foils as compared to the visual ones. Moreover, each target word was modified at the same place for the two foils, (visual or phonological); for example, at the beginning for auto (oto or outo), at the end for loup (lou or louq), or in the middle for carotte (carote versus caratte). The mean trigram frequency of each type of foils was similar (869 for the homophone foils and 1004 for the visual foils, Content and Radeau, 1988) ${ }^{3}$. Therefore, the visual foils did not present orthographic patterns more familiar than those of the phonological foils.

The children saw both the visual and the homophone foils constructed from a particular word in two different lists. The first list contained half of each kind of foils, 5 homophone foils and 5 visual foils (for example oto and louq) and the second list the other half (for example, outo and lou). Order was counterbalanced and the two presentations were separated by a week.

A relatively small number of experimental items (10 foils in each list) was used because it is difficult to work with a larger sample of experimental items, at the beginning of the study the children were very young and their vocabulary limited, at least for written words. It should be noted that before the beginning of this study, we ascertained that the children were likely to know -- orally -- all the words used to derive the experimental pseudowords and that these words could be easily used in a semantic categorization task. This was assessed in a pilot study with another group of beginning first graders.

Twenty-eight fillers (14 for each list), which were correct exemplars of a particular category, were added to the experimental list of pseudowords. The fillers, extracted from first grade readers, had approximately the same characteristics as the homophone and the visual pseudoword foils (frequency, length, spelling pattern). It should be noted that the correct words used to construct the experimental items were never presented as stimuli. All the items, experimental pseudowords (homophone and visual pseudoword foils), as well as words fillers, are presented in the Appendix. 
The test was administered to the children individually on a computer. The name of the category was first given to the children orally by the computer tape recorder, and, immediately after, the target word (filler [correct], homophone foil or visual foil) was presented in the center of the computer screen. A font $(7 \times 5 \mathrm{~mm}$.) comparable to that used in readers was designed especially for this study. Children were required to judge whether the target item (word fillers and experimental pseudowords ${ }^{4}$ ) was an exemplar of a particular semantic category. For example, the voice in the computer said, "Is it an animal?" just after the item appeared on the computer screen. If the children answered too quickly, we added while repeating the instructions that they have to look carefully at what is written and to answer only when they are sure of the response. Sometimes, especially in the first session but rarely in the second and third sessions, children read the items aloud. When this happened, we repeated the instructions, i.e., that they should read silently, not aloud.

One half of the computer keyboard was covered by a flexible green cardboard mask for the "yes" answers and the other half by a red one for the "no" answers. Five familiarization trials were given before the test. No feedback was given to the children on the nature of their responses during the practice or during the test. The children took this test three times, in January and June of first grade and in June of second grade.

\section{$\underline{\text { Analyses }}$}

The analyses were conducted only for accuracy. The data for latency were not analyzed for two reasons. First, there was a small number of correct responses; for example, less than $19 \%$ for the two types of pseudowords in the first session, $10 \%$ for the homophone foils and $30 \%$ for the visual foils in the second session. As noted by Jared \& Seidenberg (1991, p.365), conclusions based on decision times are not considered to be meaningful when the data are from less than $50 \%$ of relevant presented items. Second, some latency data were invalid, due to the fact that some children gave rapid inaccurate responses, and others, who were more accurate, took a longer time to respond. Olson, Forsberg, Wise and Rack (1994), in a review of the literature, also noted that invalid latency data, which do not correlate with accuracy, are often obtained in silent reading tasks. Moreover, since our aim was to evaluate the impact of phonological mediation in a silent reading task, we compared the accuracy data only for the two kinds of foils (homophone and visual foils).

\section{Results}

There was no significant effect of the order of presentation (first session, $\underline{F}[1,46]=0.01$, second session, $\underline{F}[1,46]=2.54, \underline{p}>.10$; third session $3, \underline{F}[1,46]=1.25)$. Therefore, we analyzed the results for the entire sample (48 subjects). The analysis of variance was conducted on the two main factors: Session (first, second and third session) and Type of foil (homophone vs. visual foils). The data are shown in Table 1.

Table 1. Semantic categorization task: Mean number for correct responses on homophone and visual foils $(\max =10)^{a}$

\section{Homophone foil}

Session 1 (first grade, January)

Session 2 (first grade, June)

Session 3 (second grade, June

a Standard deviations are in parentheses
$1.69(1.56)$

$1.04(1.60)$

$2.31(2.60)$

\section{Visual foil}

$1.81(1.68)$

$3.02(2.19)$

$4.63(3.15)$

All main effects were significant (Session, $\underline{F}[2,94]=11.00, \underline{p}<.01$; Type of foil, $\underline{F}[1,47]=$ $46.73, \underline{p}<.01)$. There was also an interaction between these two main effects $(\underline{F}[2,94]=21.27, \underline{p}<$ $.01)$. This interaction may be explained by the fact that the differences between the number of correct responses on visual foils and on homophone foils increased with sessions. In fact, for the first session we found no difference between the two kinds of foils $(\underline{F}[1,47]=0.25, \underline{p}>.10)$ while for the second 
and the third sessions, there was an effect of the type of foil (second session: $\underline{F}[1,47]=36.98, \underline{p}<.01$; third session: $\underline{F}[1,47]=52.38, \underline{p}<.01)$, homophone foils being less well detected than visual foils. Moreover, homophone foils were less well detected in the second session than in the first one $(\underline{F}[1,47]$ $=5.14, \underline{p}<.05)$. At the same time, the detection of visual foils improved $(\underline{F}[1,47]=14.33, \underline{p}<.01)$. Between the second and the third session, the performance improved for the two types of foils (for homophone and for visual foils respectively: $\underline{F}[1,47]=7.27, \underline{p}<.01 ; \underline{F}[1,47]=12.80 \underline{p}<.01$ ).

\section{Discussion}

Altogether, homophone foils produced more incorrect responses than visual foils and the difference between the two types of foils increased with time (as indicated by the interaction between type of foils and sessions). The last result is mainly explained by the fact that homophone foils were less well detected than the visual ones only in the second and third sessions. We also observed a decline in performance on the homophone foils between the first and the second session. At the same time, the performance improved for visual foils. Since the shape of the words used to construct foils was less well preserved in the case of phonological foils as compared to visual ones, these results clearly indicated that the phonological features of the items have a greater influence on the children's performance than the visual features. They also indicated that phonological mediation was used in a silent word reading task and that the strength of this procedure increased between sessions (see Casalis, 1994, for a similar result with French children).

However, the results obtained in the present semantic categorization task might be due to an imprecise knowledge of the word spelling. The following study was designed to test this hypothesis.

\section{STUDY 2}

The objective of this study was to evaluate whether the children knew the spelling of the exemplars used in the preceding task, and, more generally to assess their orthographic skills. Although there is general agreement on measures of phonological skills, there is no agreement on measures of orthographic skills (e.g. Olson et al., 1994). For example, Olson et al., 1994 (see also Stanovich \& Siegel, 1994) noted that exception word reading which allows the evaluation of "sight vocabulary" is not a true measure of orthographic skills since exception words may also be partially processed by phonological mediation because they often have regular correspondences. Moreover, comparative data between disabled and non disabled readers obtained with orthographic tasks are sometimes contradictory. For example, Olson, Wise, Conners and Rack (1990) found no inferiority on exception word reading tasks of disabled readers compared to normal readers matched in reading level. On the other hand, Manis, Szeszulski, Holt and Graves (1990) reported inferiority of the disabled readers in lexical verification and homonym tasks in which each item was presented alone. Yet, Manis (quoted in Olson, Kliegl, Davidson \& Foltz, 1985) and Stanovich and Siegel (1994) found no difference between disabled and non disabled readers (reading level matched) in an orthographic choice task in which the items were presented simultaneously. Since the results appear to be more consistent with this last task, in our study we used an orthographic choice task with three items simultaneously presented, one correct and two foils. The items were the same as the ones we used in the semantic categorization task.

\section{Method}

Subjects: The group of children was the same as for the semantic categorization task. 
$\underline{\text { Task and procedure }}$

In this orthographic choice task, we presented 10 sets of items, a correctly spelled word and two foils, a phonological one and a visual one (for example, pomme, pome, pomne). The children had to choose the "right word", i.e., the one which was spelled correctly.

These items were the same as those used in the semantic categorization task and the correct exemplar was given to the children at the same time as the two foils. For each set of items, the presentation of the exemplar, the homophone foil, and the visual foil was in a different order. This task was presented to the children, after the semantic categorization task, during the three test sessions (in January and June for first grade and in June for second grade).

\section{Results}

For correct responses, the analysis of variance was conducted on the main factor Session (first, second and third session). The results are shown in Table 2. We observed that the number of correct responses more than doubled between the first and the last session and that, by the end of second grade, most children were able to recognize the correct spelling of the words.

The ANOVA indicated that the session effect was significant $(\underline{F}[2,94]=148.41, \underline{p}<.01)$. There were also significant differences between the first and the second session $(\underline{F}[1,47]=77.92, \underline{p}<.01)$ and between the second and the third session $(\underline{F}[1,47]=68.71, \underline{p}<.01)$.

Table 2: Orthographic choice task: Mean number for correct responses $(\text { maximum }=10)^{a}$

Session 1 (first grade, January) Session 2 (first grade, June) Session 3 (second grade, June)

$4.21(1.61)$ $6.73(1.87)$

$8.69(1.59)$

a Standard deviations are in parentheses

For the error analysis, we calculated the mean percentage of each error category, i.e,. erroneous choice of the phonological foils or of the visual foils. This percentage was calculated on the basis of the total number of errors produced during each session by each child. Comparisons were made on the basis of these percentages. Since some subjects gave the maximum number of correct responses in the second and the third session, but not in the first one, there were some missing cells: 2 x 2 for the second session ( 2 children $\times 2$ types of errors); and $19 \times 2$ missing cells for the third session.

The results of the error analyses are presented in Table 3. We observed that more than $78 \%$ of the errors for the two first sessions and more than $66 \%$ for the third one involved the phonological foils. The statistical analysis confirmed that homophone foils were chosen more often than visual foils for the three sessions (for the first, the second and the third session respectively, $\underline{\mathrm{t}}(47)=10.95, \mathrm{p}<.01 ; \mathrm{t}(47)=$ $10.99, \mathrm{p}<.01 ; \mathrm{t}(47)=3.84, \mathrm{p}<.01)$. The results of the third session are to be considered with caution as 19 children (out of 48) made no errors at all.

Table 3: Orthographic choice task: Mean percentage of errors on homophone and visual foils a

\section{Homophone foil}

Session 1 (first grade, January)

Session 2 (first grade, June)

Session 3 (second grade, June)

a Standard deviations are in parenthese
$78.34(17.93)$

$84.47(21.73)$

$66.03(28.89)$

\section{Visual foil}

$21.66(17.93)$

$15.53(21.73)$

$33.97(28.89)$

\section{Discussion}

At the end of second grade, the children's orthographic skills were quite well established, at least for the simple items used in that study ( $86.9 \%$ of responses were correct). These results are similar to those reported in the literature. For example, in the Barker, Torgesen and Wagner's study 
(1992), children a little older than ours (third graders from 9 to 10 year old) made $83 \%$ correct responses in an orthographic choice task that involved choices between a real word and a homophone foil and $88 \%$ correct responses in a homophone choice task between two real words. With children of approximately the same age as our second graders, Manis et al. (1990, see also Manis, Custodio \& Szeszulski, 1993) noted between 70 and $87.6 \%$ of correct responses in different orthographic verification tasks that did not imply a choice between items but a decision on the status of a particular item (lexical verification, homonym verification and lexical decision).

In our study, whereas at the end of second grade, the children made very few errors in the orthographic choice task, at the same time and for the same items in the semantic categorization task there were only $34.7 \%$ correct responses of which $23 \%$ were for the homophone foils and $46 \%$ for the visual foils. Therefore, the high number of errors observed on the homophone foils is not due to imprecise orthographic knowledge. The difference between the semantic categorization task and the orthographic one could partially be explained by the fact that the latter task is easier than the former as the correct exemplar was presented at the same time as the two foils. This, however, does not explain why, between the first and second session, the number of correct responses for the homophone foils decreased in the semantic categorization task when at the same time the children's performance improved in the orthographic task.

The analysis of the errors also showed that in the orthographic choice task as well as in the semantic categorization task, the children made more errors on the homophone foils than on the visual foils. The results of the last session should, however, be interpreted with caution as 19 children made no error at all. (Only two children at the end of first grade and none in January of the same year made no errors at all).

It seems worthwhile to examine the performance in the semantic task of the 19 children who recognized the correct spelling for all of the items used in the orthographic choice task. If phonological mediation is a mechanism which reinforces the knowledge of spelling to sound correspondences and, to a larger extent, the knowledge of mapping between orthography and phonology (Share, 1995), these 19 subjects who we called "expert" spellers, should be the children who relied more on phonological mediation. This hypothesis is the starting point of the next study.

\section{STUDY 3}

In order to determine if phonological skills contribute to the construction of the orthographic lexicon, we compared the results obtained by two subgroups of children: (a) the 19 so-named "expert" spellers who made no errors in the orthographic choice task at the end of second grade, and (b) the 7 children who made the greatest number of errors in the same task, who we called "poor" spellers. For those two subgroups of subjects, we compared:

(a) the change, between the first and second grade, in their performance in the semantic categorization task,

(b) their earlier phonological skills assessed by pseudoword reading and spelling tasks in first grade,

(c) their earlier performance in kindergarten (before reading acquisition) in phonological awareness,

(d) non verbal IQ (Raven matrices scores) and oral vocabulary at the same time in order to verify if the difference in spelling expertise is not due to differences at these two levels.

$\underline{\text { Subjects }}$

\section{Method}

We examined the results in the semantic categorization task, as well as in other tasks administered at different times, for the two subgroups established on the basis of their performance in 
the orthographic choice task (see Study 2). One subgroup, the expert spellers, included the 19 children who made no errors in this task at the end of second grade. The second subgroup included the 7 poor spellers who obtained the lowest scores in this task at the same time ( 3 or more errors out of 10$)$.

Tasks and procedure

The performance of these two subgroups were assessed in the semantic categorization task in the first and second grade. We also assessed their phonological skills by a pseudoword reading aloud task and by a spelling task in first grade. For these two tasks, we used the same items, i.e. is simple regular pseudowords (i.e., pseudowords with only simple graphemes, 4 items) and regular complex pseudowords (pseudowords including complex graphemes such as "ou" or "ch", 4 items). These pseudowords are presented in the Appendix.

Each child was asked to read each item aloud when it appeared on the computer monitor and was told that the items were words from "Martian language". A font $(7 \times 5 \mathrm{~mm})$ comparable to the one used in readers was designed especially for the experiment. There were three familiarization trials which could be re-administered if the child failed to understand the instructions. Based on pilot results, the test items were displayed on the screen for a maximum of seven seconds. All test items were presented in one session, and no feedback was provided. The responses were recorded during the test session both by the experimenter and the computer. The same items were dictated to the children in small groups of two or three. The spelling task was administered one week after the reading task in the January and the June sessions of first grade. Because of the regularity of the items, the coding of the responses was not difficult. For the reading task, a response was considered correct if the child gave a pronunciation which was consistent with French grapheme-phoneme correspondences; for the spelling task, we considered as correct all spellings which would be pronounced the same way as the item which was dictated to the child.

In the last year of kindergarten, phonological awareness skills had been assessed by a rhyme task and by syllable and phoneme deletion tests. Items used for these tests were all pseudowords to prevent biases resulting from the vocabulary knowledge of children (see Appendix). The first test was a same/different rhyme and alliteration task for monosyllabic items. There were four subtests of ten

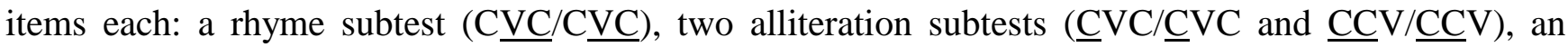
onset + nucleus subtest $(\underline{\mathrm{CVC}} \underline{\mathrm{CVC}})$. For each subtest, one half of the items shared the same test element. The children were asked if "they heard the same thing at the end" (rhyme subtest) or "at the beginning" (alliteration and onset + nucleus subtests) of two "made-up words". The second test involved an initial syllable deletion from two-syllable items (CV/CV). The third involved an initial phoneme deletion from two-phoneme items (CV). For the deletion tasks, the children were told not to say the beginning of a "made-up word".

For each of the three tests, before the presentation of the test items, the children were given practice items. All three tests were presented on a tape recorder. The order of presentation was as follows: 1. rhyme and alliteration test (rhyme, alliteration 1 and 2, onset + nucleus subtests), 2. syllable deletion test, 3. phoneme deletion test. The children were tested individually. During the test session, no feedback was provided. These three tasks were given in December, at the beginning of the last year of kindergarten (age 5 years).

At the same time, the non verbal cognitive level of those children was assessed by the Raven's progressive matrices. We also assessed their oral vocabulary knowledge by a French standardized vocabulary test for 5-8 year old children (Deltour \& Hupkens, 1980). First, the children had to give the definition of a word (for example, hiver, [winter]) and, second, to select, among 5 pictures, the one corresponding to the word previously presented. The children were presented with 30 words. The maximum score for each word was two points. 
$\underline{\text { Semantic categorization task }}$

\section{Results}

The results are shown in Figure 1. The analysis of variance was conducted on the main factors: Session (first, second and third session), Type of foil (homophone vs. visual foils), and Group (expert vs. poor spellers). We observed a main effect for Session $(\mathrm{F}[2,48]=15.11, \mathrm{p}<.01)$ and for foils $(\underline{F}[1,24]=44.67, \underline{p}<.01)$; there was no effect for Group $(\underline{F}[1,24]=2.84, \underline{p}>.10)$. However, the Session $x$ Group interaction was significant $(\underline{F}[2,48]=11.42, \underline{p}<.01)$. All the other interactions were not significant (Group $x$ Type of foil, $\underline{F}[1,24]=3.02, \underline{p}>.10$; Group $x$ Type of foil $x$ Session, $\underline{F}[2,48]=$ $1.97, \mathrm{p}>.10$ ). The Group $x$ Session interaction was due, on the one hand, to the fact that there was no significant difference between the first and the second session between the two groups $(\underline{F}[1,24]=2.01$, $\mathrm{p}>.10)$ and, on the other hand, to the fact that the scores of the expert spellers increased more than those of the poor spellers between the second and the third session $(\underline{F}[1,24]=4.54, \underline{p}<.05)$.

Figure 1. Semantic categorization task: Correct responses for expert/poor spellers (maximum=10)

\section{Semantic categorisation task: Correct responses for "Expert"/"Poor" in spelling (maximum=10)}

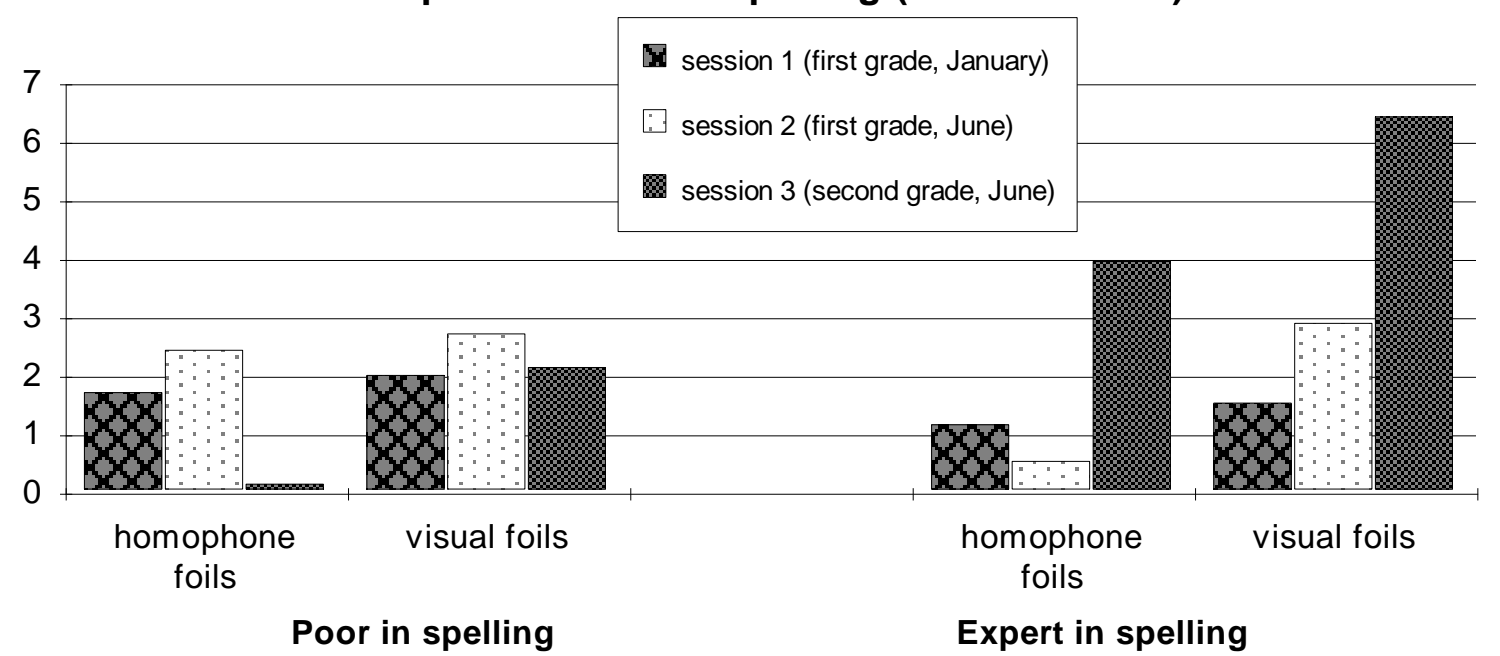

Separate analyses for each subgroup indicated main effect for session $(\underline{F}[2,36]=24.32, \underline{p}<.01)$ and for type of foil $(\underline{F}[1,18]=35.55, \underline{p}<.01)$ for the expert spellers. We also observed a Session $\mathrm{x}$ Type of foil interaction $(\underline{F}[2,36]=9.21, \underline{p}<.01)$ due to the fact that the negative impact observed for homophone foils increased between sessions. Separate analyses for each session indicated better scores for visual foils than for homophone foils only from the end of first grade (type of foil effects for the sessions one, two and three, respectively, $\underline{\mathrm{F}}[1,18]=1.35, \underline{\mathrm{p}}>.10 ; \underline{\mathrm{F}}[1,18]=22.72, \underline{\mathrm{p}}<.01 ; \underline{\mathrm{F}}[1,18]=$ $28.77, \mathrm{p}<.01)$. Moreover, the performance obtained by the expert spellers for the homophone foils did not increase significantly between the middle and the end of first grade $(F[1,18]=3.07, p>.10)$ while there was an improvement for visual foils between these two periods $(\underline{F}[1,18]=4.99, \underline{p}<.05)$. The experts' performance also improved between the end of first grade and the end of second grade for homophone foils $(\underline{F}[1,18]=26.93, \underline{p}<.01)$ and for visual foils $(\underline{F}[1,18]=39.11, \underline{p}<.01)$.

For the subgroup of poor spellers, a difference was observed between the two kinds of foils $(\underline{F}[1,6]=12.79, \underline{p}<.05)$ with lower scores for homophone foils than for visual foils. However, in this subgroup, performance did not improve between sessions $(\underline{F}[2,12]=1.24, \underline{p}>.10)$ and did not change 
with time according to the type of foils (Session $x$ Type of foil interaction, $\underline{F}[2,12]=2.31, \underline{p}>.10$ ). Separate analyses for each session indicated that these subjects selected the homophone foils less well than the visual foils only in the third session $(\underline{F}[1,6]=7.00, \underline{p}<.05)$. Except for this latter result, we observed no significant difference in the benefit of visual or homophone foils in the two other sessions in this subgroup (effect of the Type of foil for the first session, $\underline{F}[1,6]=0.36, \underline{p}>.10$ and for the second session, $\underline{F}[1,6]=0.36, \underline{p}>.10)$. Also, there was no significant improvement in performance between sessions for these children, neither for homophone foils (between sessions one and two, $\underline{F}[1,6]=0.35, \underline{p}$ $>.10$ and between sessions two and three, $\underline{F}[1,6]=4.63, \underline{p}>.05$ ) nor for visual foils (between sessions one and two, $\underline{F}[1,6]=0.60, \underline{p}>.10$; between sessions two and three, $\underline{F}[1,6]=0.20, \underline{p}>.10$ ).

In summary, the main differences between the expert and the poor spellers are due, on the one hand, to the fact that the expert, but not the poor spellers, were less accurate in detecting phonological foils than visual foils from the end of first grade. On the other hand, the performance of the experts, but not those of the poor spellers, improved between the end of first grade and the end of second grade.

\section{Phonological skills in first grade}

The results obtained in first grade in pseudoword reading and spelling by children who were expert or poor spellers at the end of second grade are shown in Table 4. We observed that the scores obtained by the experts were systematically better than those obtained by the poor spellers. Except for the January session in reading, all those differences were significant (for the January session, reading, $\underline{\mathrm{t}}[24]=1.28, \underline{\mathrm{p}}>.10$, spelling, $\underline{\mathrm{t}}[24]=2.16, \underline{\mathrm{p}}<.05$; for the June session, reading, $\underline{\mathrm{t}}[24]=2.26, \underline{\mathrm{p}}<.05$, spelling, $\underline{\mathrm{t}}[24]=2.28, \underline{\mathrm{p}}<.05)$.

Table 4: Phonological skills (pseudowords reading/spelling) for the expert and the poor spellers: First grade

\begin{tabular}{lllll} 
& & \multicolumn{3}{c}{$($ January and June Sessions) } \\
& $\begin{array}{l}\text { Reading } \\
\text { January } \\
\text { (/8) }\end{array}$ & $\begin{array}{l}\text { Spelling } \\
\text { January (/8) }\end{array}$ & $\begin{array}{l}\text { Reading June } \\
(/ 8)\end{array}$ & $\begin{array}{l}\text { Spelling } \\
\text { June }\end{array}$ \\
& $4.53(2.91)$ & $4.74(2.66)$ & $7.00(1.70)$ & $6.68(1.42)$ \\
Expert spellers & $2.86(3.02)$ & $2.14(2.85)$ & $5.00(2.71)$ & $4.86(2.67)$ \\
Poor spellers & & &
\end{tabular}

a Standard deviations are in parentheses

Phonological awareness, vocabulary knowledge and non verbal IQ in kindergarten

The results obtained in the last year of kindergarten (in December) by the expert and the poor spellers are shown in Table 5. For all the phonological awareness tests, scores obtained by the expert spellers were better than those obtained by the poor spellers. The differences were significant for the rhyme task $(\underline{\mathrm{t}}[24]=2.10, \underline{\mathrm{p}}<.05)$ and for the phoneme task $(\mathrm{t}[24]=2.29, \underline{\mathrm{p}}<.05)$. For the syllable task, the difference did not reach a conventional level of significance $(\underline{\mathrm{t}}[24]=2.04, \underline{\mathrm{p}}<.06)$.

Table 5: Phonological awareness skills, IQ and vocabulary knowledge in the last year of kindergarten (in December)

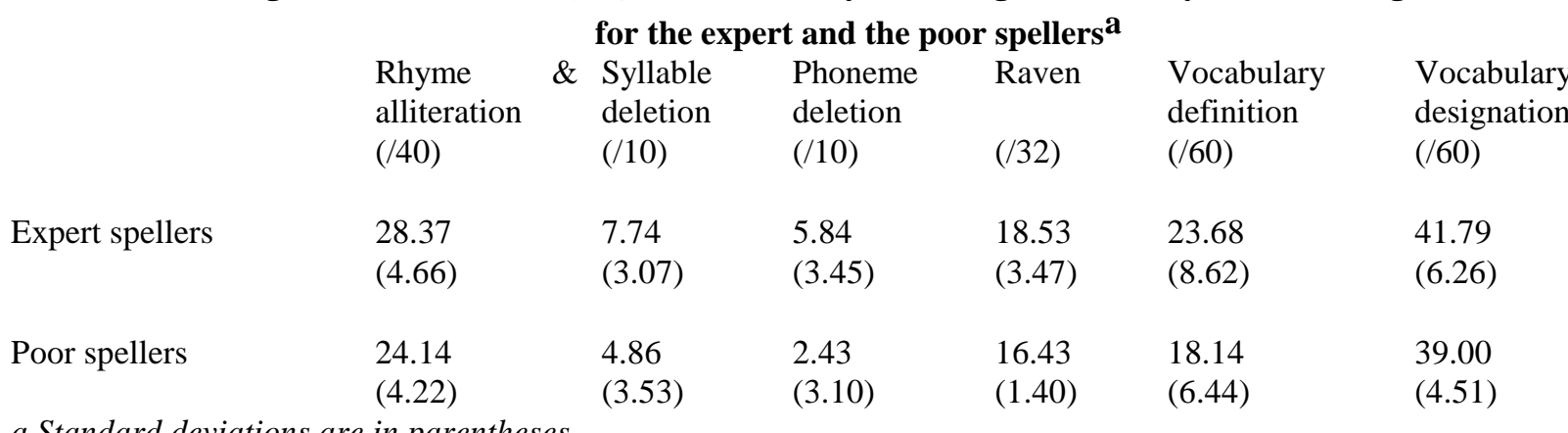

a Standard deviations are in parentheses 
We observed no significant differences between those two subgroups of children for the results on Raven's progressive matrices $(\underline{\mathrm{t}}[24]=1.53, \underline{\mathrm{p}}>.10)$, and for the two vocabulary tasks (designation and definition respectively, $\underline{\mathrm{t}}[24]=1.54, \underline{\mathrm{p}}>.10 ; \underline{\mathrm{t}}[24]=1.07, \underline{\mathrm{p}}>.10)$. It is important to note that, at that time, as well as at the end of kindergarten, those children showed no difference in their reading level as they were all non-readers according to a standardized reading test.

\section{Discussion}

We observed a differential developmental trend in the semantic categorization task for the two subgroups classified as expert and poor spellers at the end of second grade. First, there were no differences in the processing of the phonological foils as compared to the visual foils in the first session (January of first grade), neither for the future expert spellers, nor for the future poor spellers. However, at the end of first grade, the future expert spellers, but not the future poor spellers, made more errors on the homophone foils than on the visual foils; the same result was observed for both subgroups at the end of second grade. Second, the performance of the expert spellers, but not those of the poor ones, improved between the end of first grade and the end of second grade. Therefore, the expert spellers at the end of second grade were the children who used phonological mediation most strongly at the end of first grade and were also those whose performance improved the most in the semantic categorization task. This result may be considered as an indicator of the fact that using phonological mediation in the early stage of reading acquisition is a mechanism which allows reading learners to construct their orthographic lexicon.

The same tendency was observed in the comparisons of the early phonological skills of these two subgroups as measured by pseudoword reading and spelling tests in the middle and the end of first grade. Except for the results of the first session for the reading test, the future expert spellers had better scores than the poor spellers. These results were obtained even though we selected children at the same (non) reading level at the end of kindergarten.

The results at the beginning of kindergarten also indicated that only the skills related to phonological mediation differentiated these two subgroups of subjects. At the beginning of the last year of kindergarten, the future expert in spelling had significantly better performance than future poor spellers in two out of the three phonological awareness tasks (the rhyme task and the phoneme deletion task). For the syllable deletion task, the difference did not reach a conventional level of significance. At the same time, these children did not differ in their non verbal cognitive level or in their vocabulary knowledge. These data may be interpreted as an indicator of the fact that phonological awareness, being related to phonological recoding skills in both reading and spelling, would make the further construction of the orthographic lexicon easier (see Share, 1995). This seems to be independent of non verbal cognitive level and of vocabulary knowledge.

\section{GENERAL DISCUSSION}

The results indicated that phonological mediation played an important role in silent reading. In a semantic categorization task, the differences between phonological and visual foils increased with time to the detriment of the phonological foils for which we even observed a decline of performance between the middle and the end of first grade.

These results, particularly those of the third session, at the end of second grade, cannot be attributed to poor orthographic knowledge of the words used in those studies, since at that time the children's scores in the orthographic choice task were actually high: $86.9 \%$ of responses were correct as compared to less than $25 \%$ for the phonological foils in the semantic categorization task. Similarly, the 
errors in the orthographic choice task indicated that the children were more likely to choose the phonological foil rather than the visual one, although the latter preserved more accurately the shape of the correct word. The fact that the phonological foils were chosen more often than the visual foils in the semantic and in the orthographic tasks shows the importance, at that time, of phonological mediation in silent reading.

Moreover, the decrease of performance for the phonological foils in the semantic categorization task between the first and the second sessions is inconsistent with the fact that, as reading level improves, orthographic representations are expected to become more precise. Therefore, we should logically observe fewer errors -- and not more -- on all kinds of foils, including phonological ones. This improvement in performance was actually observed between the first and second session in the orthographic choice task. Thus, while the results of the orthographic choice task indicated the progressive establishment of an orthographic lexicon, those obtained in the semantic categorization task indicated that, at the same time, phonological procedures still exert a significant influence on reading.

The same type of results were obtained in reading aloud tasks in a preceding study with the same children (see Sprenger-Charolles, Siegel \& Béchennec, 1997). In that study, we observed an early stage (middle of first grade) in which children primarily used phonological mediation as indicated by the significant effect of regularity and by the lack of frequency and lexicality effects. Nevertheless, they were able to quite rapidly construct an orthographic lexicon. Support for this interpretation comes from the fact that frequency and lexicality effects were observed only at the end of first grade. Although children used orthographic processing in a later stage of reading, this procedure did not entirely replace phonological mediation. Evidence for this position was provided by the greater regularity effect observed at the end of first grade than in the middle of the same grade. Moreover, we observed that the errors which we have attributed to phonological processing (regularization errors) increased with time. These data, as those obtained in the silent reading tasks, suggest that orthographic and phonological processing may be used at the same time.

The results obtained in the semantic categorization task by two subgroups of children who differed according to their level of orthographic expertise at the end of second grade indicated, as noted earlier, a differential developmental trend. There were no differences in processing the phonological foils, as compared to the visual ones, in the middle of first grade, neither for the future expert spellers, nor for the future poor spellers; at the end of the same grade, only the future expert spellers made more errors on the homophone foils than on the visual foils. This last result was observed for both subgroups at the end of second grade. Moreover, the performance of the expert spellers, but not those of the poor ones, improved between the end of first grade and the end of second grade. Therefore, expert spellers appear to develop phonological skills earlier than poor spellers, but the developmental trajectory of these two subgroups does not seem to differ. The differences were reflected more in the developmental pace, than in the route by which the orthographic lexicon was constructed. This result suggests that there may be only one way to set up an orthographic lexicon, and supports the hypothesis of a developmental dependence of the direct route upon the indirect phonological one. This interpretation was also supported by the fact that the expert spellers obtained higher scores than the poor spellers in other phonological tasks (pseudoword reading and spelling) in first grade and higher scores in phonological awareness tasks in kindergarten. It should be added that these two subgroups did not differ on their non verbal cognitive skills or on their oral vocabulary level assessed at the same time as their phonological awareness skills (in kindergarten).

Close links between tasks evaluating phonological and orthographic skills (orthographic choice) in beginning readers were also apparent in the studies of Olson et al. (1990, see also for a review Olson et al., 1994). The correlations between these two types of tasks were .49 for a group of younger children without dyslexia. Similarly, in another study with some of the same children as in the present 
one, we have found high and significant correlations between early phonological skills (pseudoword reading and spelling in the middle of first grade) and later orthographic skills evaluated at the end of the same grade by an irregular word reading and spelling task (.61 both in reading and in spelling). On the contrary, there were no significant correlations between early performance on irregular words and later results on pseudowords or regular words. We have also observed positive and significant correlation between correct responses and regularization errors in the middle of first grade, both in reading and in spelling (Sprenger-Charolles, Siegel \& Béchennec, 1997; see also Sprenger-Charolles, Siegel \& Bonnet, in press. The same type of results was observed by Byrne et al. (1992), Gough and Walsh (1991), Stanovich and West (1989).

These results, in addition to those obtained by Jorm et al. (1984) in their longitudinal study of children who differed in kindergarten in their phonological recoding skills and by Byrne et al. (1992) on studies comparing "Chinese" and "Phoenician" readers, illustrate the role of phonological skills in constructing an orthographic lexicon for reading (see Share, 1995 for a review).

The role of phonological skills in the construction of the orthographic lexicon in reading might be explained, as we have suggested in the conclusion of another longitudinal study (SprengerCharolles, Siegel \& Béchennec, 1997), by the fact that the use of phonological mediation, facilitated by phonological awareness, permits reading known or unknown regular words as well as pseudowords. The use of this procedure and the confrontation between the result of a(n) -- even partial -phonological recoding and words that are part of the oral vocabulary allow children to infer graphemephoneme correspondences (GPC). As French has a highly regular orthography, the majority of words can be read in this manner. It is important to note that even irregular words contain some regular correspondences. Moreover, it is possible to conceive that certain irregularities are only a question of grapheme frequency. For example, "e+m" in femme is read /a/ as in adverbs ending with "emment" (such as fréquemment). In this case, confrontation with the oral lexicon also permits the learning of this association leading to the inference that "e" must be read as /a/ in this context (since the word /f $\partial \mathrm{m} /$ does not exist in French, but that a very close high frequency word, /fam/, exists). It seems reasonable to postulate that children learn most of the relationships between orthography and phonology by this procedure. As a function of grapheme and word frequency, the strong associations between orthographic and phonological units allow for a gradual construction of the orthographic lexicon which permits the use of the direct route. Nevertheless, even when the direct route is functional, children may still have recourse to phonological mediation which becomes more and more sophisticated as a result of reinforcement of associations. This way of learning to read is similar to the one developed in the Coltheart et al.'s (1993) connectionist model.

The interpretation of our results offers understanding why, at the same time, we observed an increase in the use of phonological mediation and the setting up of the orthographic lexicon. These findings partially fit Ehri's (1992) model in which phonological mediation and orthographic knowledge develop simultaneously and are mutually reinforcing. They also support Share's (1995) arguments showing the importance of phonological mediation in setting up the orthographic lexicon. On the other hand, our results cannot be completely explained by strict stage models since we observed no point where phonological processing seems to decline as would be expected according to the Frith's (1986) and Morton's (1989) models. This decline might occur later. We hope to be able to answer this question by analyzing the results obtained by our children in the following grades (grade 3 and 4 ). 
Notes

1. We do not consider, in the present article, the fact that in these developmental models the indirect phonological stage and the direct orthographic stage are assumed to be preceded by a "prereading" logographic stage. At this stage, written words are assumed to be identified on the basis of the non linguistic context and visual indices: overall shape or a specific salient configuration for example. This omission may be explained, first, because we do not intend to evaluate prereading strategies and, second, because it seems that this type of strategy is unimportant in languages which have more regular spelling to sound correspondences than English (see Wimmer \& Hummer, 1990; Wimmer \& Goswami, 1994 for German speaking children and Sprenger-Charolles \& Bonnet, 1996, for French speaking children).

2. This constraint was respected for all items excepted one: "rouje" for rouge.

3. The trigram frequency has been calculated according to Content and Radeau's (1988) study, and takes into account the position of each trigram in the words. Words used for the Content and Radeau's study were the 30.000 items of a French Dictionary. The authors also gave a second indicator ponderated by word frequency. According to this indicator, the trigram frequency of our homophone was less than the frequency of visual foils (323 as compared to 860). Therefore, the orthographic pattern of our visual foils should be more familiar to the children. We used the first indicator because the word frequency was established on a corpus which is not representative of the children's language.

4. It is possible that children simply made a word/pseudoword decision to answer, since our experimental items (no responses) were all pseudowords and our fillers were all words (yes responses). However, our aim was to test the difference between the two kinds of pseudowords (homophone and visual foils) and not the difference between words and pseudowords. 


\section{References}

Backman, J., Bruck, M , Hebert, M. \& Seidenberg, M.S. (1984). Acquisition and use of spelling sound correspondences in reading. Journal of Experimental Child Psychology, 38, 114-133.

Barker, T.H., Torgesen, J.K. \& Wagner, R.K. (1992). The role of orthographic processing skills on five reading tasks. Reading Research Quarterly, 27, 335-345.

Byrne, B., Freebody, P. \& Gates, A. (1992). Longitudinal data on the relations of word-reading strategies to comprehension, reading time and phonemic awareness. Reading Research Quarterly, 27, 141-151.

Casalis, S. (1994). Dyslexie développementale et apprentissage de la lecture, Thèse de Doctorat, Université de Lille III.

Coltheart, M., Curtis, B., Atkins, P \& Haller, M. (1993). Models of reading aloud: Dual route and parallel processing approaches. Psychological Review, 100, 589-608.

Coltheart, V., Laxon, V., Rickard, M. \& Elton, C. (1988). Phonological recoding in reading for meaning by adults and children. Journal of Experimental Psychology: Learning, Memory and Cognition, 14, 387-397.

Coltheart, V., Patterson, K \& Leahy, J. (1994). When a rows is a rose: phonological effects in written word comprehension, Quarterly Journal of Experimental Psychology, 47, 917-955.

Content, A., \& Radeau, M. (1988). Données statistiques sur la structure orthographique du Français. Cahiers de Psychologie Cognitive/European bulletin of Cognitive Psychology. Special issue, 87p.

Deltour, J.J. \& Hupkens, D. (1980). Test de vocabulaire actif et passif pour enfants (5 à 8 ans). Issy-les-Moulineaux, E.A.P.

Doctor, E. \& Coltheart, M. (1980). Phonological recoding in children's reading for meaning. Memory and cognition, $\underline{80}$, 195-209.

Ehri, L.C. (1992). Reconceptualizing the development of sight word reading and its relationships to recoding. In P. Gough, L. Ehri \& R. Treiman (Eds.), Reading Acquisition (pp.107-143). Hillsdale: Erlbaum.

Freebody, P. \& Byrne, B. (1988). Word-reading strategies in elementary school children: Relations to comprehension, reading time, and phonemic awareness. Reading Research Quarterly, 23, 441-453.

Frith, U. (1986). A developmental framework for developmental dyslexia. Annals of Dyslexia, $\underline{36}, 69-81$.

Gough, P.B. \& Walsh, M.A. (1991). Chinese, Phoenicians, and the orthographic cipher of English. In S.A. Brady \& D.P. Shankweiler (Eds.), Phonological processes in literacy. A tribute to Isabelle Y. Liberman (pp. 199-209). Hillsdale, N.J.: Lawrence Erlbaum Associates.

Harris, M. \& Coltheart, M. (1986). Language processing in children and adults: An introduction. London: Routledge and Kegan.

Humphreys, G., W. \& Evett, L. J. (1985). Are there independent lexical and nonlexical routes in word processing? An evaluation of the dual-route theory of reading. Behavioral and Brain Sciences, $\underline{8}, 689-740$.

Jared, D. \& Seidenberg, M.S. (1991). Does word identification proceed from spelling to sound to meaning. Journal of Experimental Psychology: General, 120, 358-394.

Johnston, R.S., Thompson, G.B., Fletcher-Flinn, C.M. \& Holligan, C. (1995). The functions of phonology in the acquisition of reading: Lexical and sentence processing. Memory and Cognition, 23, 749-766.

Jorm, A.F., Share, D.L., MacLean, R. \& Matthews, R.G. (1984). Phonological recoding skill and learning to read: A longitudinal study. Applied Psycholinguistics, 5, 201-207.

Lewellen, M.J., Goldinger, S.D., Pisoni, D.B. \& Greene, B.G. (1993). Lexical familiarity and processing efficiency: Individual differences in naming, lexical decision and semantic categorization. Journal of Experimental Psychology, General, 122, 316-330.

Leybaert, J. \& Content, A. (1995). Reading and spelling acquisition in two different teaching methods: A test of the independence hypothesis. Reading and Writing: An Interdisciplinary Journal, 7, 65-88.

Manis, F.R., Custodio, R. \& Szeszulski, P.A. (1993). Development of phonologic and orthographic skills: A 2-year longitudinal study of dyslexic children. Journal of Experimental Child Psychology, 56, 64-86.

Manis, F.R., Szeszulski, P.A., Holt, L.K. \& Graves, K. (1990). Variation in component word recognition and spelling skills among dyslexic children and normal readers. In T.H. Carr \& B.A. Levy (Eds.): Reading and its development: Component skills approaches (pp. 207-259). San Diego: Academic Press, INC., Harcourt Brace Jovanovich Publishers.

Morton, J. (1989). An Information-processing account of reading acquisition. In A. M. Galaburda (Ed.), From reading to neurons (pp. 43-66). Cambridge, MA: Bradford Book, M.I.T. Press.

Olson, R., Forsberg, H., Wise, B. \& Rack, J. (1994). Measurement of word recognition, orthographic and phonological skills. In G.R. Lyon (Ed.) Frames of reference for the assessment of learning disabilities: New views on measurement issues (pp. 243-275). Baltimore/London/Toronto/Sydney: Paul H. Brookes.

Olson, R.K., Kliegl, R., Davidson, B. \& Foltz, G. (1985). Individual and developmental differences in reading disability. In G.E. Mckinnon \& T.G. Waller (Eds.): Reading research: Advances in theory and practice, (vol. 4, pp. 1-64.). San Diego, CA: Academic Press Inc. 
Olson, R.K., Wise, B.W., Conners F. \& Rack, J. (1990). Organization, Heritability and remediation of component word recognition and language skills in disabled readers. In T.H. Carr \& B.A. Levy (Eds.): Reading and its development: Component skills approaches (pp. 261-322). San Diego: Academic Press, INC., Harcourt Brace Jovanovich Publishers.

Paap, K.R. \& Noel, R.W. (1991). Dual-route models of print to sound: Still a good horse race. Psychological Research, $\underline{53}$, $13-24$

Raven (1947, réed. 1981). Progressives Matrices Standard. Issy-les-Moulineaux: E.A.P.

Savigny, M. (1974). Manuel (forme B) pour l'utilisation des tests BAT-ELEM. Issy les Moulineaux: E.A.P.

Seidenberg, M.S. (1992). Beyond orthographic depth in reading: Equitable division of labor. In R. Frost and L. Katz (Eds.), Orthography, phonology, morphology and meaning. North Holland, Elsevier Science Publishers.

Seidenberg, M.S. \& McClelland, J. L. (1989). A distributed developmental model of word recognition and naming. Psychological Review, 96, 523-568.

Seidenberg, M.S., Plaut, D.C., Peterson, A.S., McClelland, J.L. \& McCrae, K. (1994). Nonword pronunciation and models of word recognition. Journal of Experimental Psychology: Human Perception and Performance, 20, 1177-1196.

Seidenberg, M.S., Waters, G.S., Barnes, M.A. \& Tanenhaus, M.K (1984). When does spelling or pronunciation influence word recognition? Journal of Verbal Learning and Verbal Behavior, 23, 383-404.

Seymour, P.H.K. (1986). Cognitive analysis of dyslexia. London/New-York: Routledge \& Kegan Paul.

Share, D.L. (1995). Phonological recoding and self-teaching: Sine qua non of reading acquisition. Cognition, 55, 151-218.

Sprenger-Charolles, L. \& Bonnet, P. (1996). New doubts on the importance of the logographic stage: A longitudinal study of French children, Cahiers de Psychologie Cognitive/Current Psychology of Cognition, 15, 173-208.

Sprenger-Charolles, L. \& Casalis, S. (1995). Reading and spelling acquisition in French first graders: Longitudinal evidence. Reading and Writing: An Interdisciplinary Journal, 7, 39-63.

Sprenger-Charolles, L. \& Siegel, L.S. \& Béchennec, D. (to appear). Learning to read and spell in French: Longitudinal studies. In C. Perfetti, L. Rieben \& M. Fayol (Eds.), Learning to spell._Hillsdale: Erlbaum.

Sprenger-Charolles, L., Siegel, L.S. \& Bonnet, P. (in press). Reading and spelling acquisition in French: The role of phonological mediation and orthographic factors. Journal of Experimental Child Psychology.

Stanovich, K.E. (1980). Toward an interactive compensatory model of individual differences in the development of reading fluency, Reading Research Quarterly, 16, 32-71.

Stanovich, K.E. \& Siegel, L.S. (1994). Phenotypic performance profile of children with reading disabilities: A regressionbased test of the phonological-core variable-difference model. Journal of Educational Psychology, $\underline{86}, 24-53$.

Stanovich, K.E. \& West, R.F. (1989). Exposure to print and orthographic processing, Reading Research Quarterly, 24, 402-433.

Treiman, R., Freyd, J. \& Baron, J. (1983). Phonological recoding and use of spelling-sound rules in reading of sentences. Journal of Verbal Learning and Verbal Behavior, 22, 682-700.

Van Orden, G.C. (1987). A rows, is a rose: Spelling, sound and reading. Memory and Cognition, 15, 181-198.

Van Orden, G.C., Johnston, J.C. \& Hale, B.L. (1988). Word identification in reading proceeds from spelling to sound to meaning. Journal of Experimental Psychology: Learning, Memory and Cognition, 14, 371-386.

Waters, G.S., Seidenberg, M.S. \& Bruck, M. (1984). Children's and adults' use of spelling sound information in three reading task. Memory and Cognition, $\underline{12}, 293-305$.

Wimmer, H. \& Goswami, U. (1994). The influence of orthographic consistency on reading development: Word recognition in English and German children. Cognition, 51, 91-103.

Wimmer, H. \& Hummer, P. (1990). How German speaking first graders read and spell: Doubts on the importance of the logographic stage. Applied Psycholinguistics, 11, 349-368. 


\section{Appendix}

List of items used in studies 1 and 2 (semantic categorization and orthographic choice tasks)

\begin{tabular}{|c|c|c|c|c|c|}
\hline \multirow[t]{2}{*}{ Category } & \multicolumn{3}{|c|}{$\begin{array}{l}\text { Foils (correct exemplar in the last column } \\
\text { with translation in bracket) }\end{array}$} & \multicolumn{2}{|c|}{$\begin{array}{l}\text { Fillers (used only in the semantic } \\
\text { categorization task) }\end{array}$} \\
\hline & Homophone & Visual foil & Correct exemplar & List 1 & List 2 \\
\hline \multirow[t]{2}{*}{ Animal } & lou & louq & loup (wolf) & lapin (rabbit) & chat (cat) \\
\hline & pijon & pigean & pigeon (pigeon) & chien (dog) & chien (dog) \\
\hline \multirow[t]{2}{*}{ Color } & rouje & rouqe & rouge (red) & gris (grey) & bleu (blue) \\
\hline & blan & blauc & blanc (white) & $\begin{array}{l}\text { noir (black) } \\
\text { jaune (yellow) }\end{array}$ & \\
\hline \multirow{4}{*}{$\begin{array}{l}\text { Fruit \& vegetable; } \\
\text { something to eat }\end{array}$} & frèze & froise & fraise (strawberry) & poire (pear) & tomate (tomato) \\
\hline & pome & pomne & pomme (apple) & salade (salad) & banane (banana) \\
\hline & carote & caratte & carotte (carrot) & $\begin{array}{l}\text { purée (mashed } \\
\text { potatoes) }\end{array}$ & $\begin{array}{l}\text { prune (plum) } \\
\text { pêche (peach) }\end{array}$ \\
\hline & & & & soupe (soup) & \\
\hline \multirow{3}{*}{$\begin{array}{l}\text { Means of transport; } \\
\text { something use } \\
\text { to travel }\end{array}$} & trin & troin & train (train) & moto (motor cy & avion (plane) \\
\hline & oto & outo & auto (car) & & bus (bus) \\
\hline & vélau & véla & vélo (bike) & & \\
\hline Dishes & & & & bol (bowl) & $\begin{array}{l}\text { couteau (knife) } \\
\text { verre (glass) }\end{array}$ \\
\hline Clothes & & & & $\begin{array}{l}\text { manteau (coat) } \\
\text { chemise (shirt) }\end{array}$ & pantalon (trousers) \\
\hline \multicolumn{4}{|l|}{ Flowers } & & tulipe (tulip) \\
\hline \multicolumn{4}{|l|}{ First name } & Bruno & Luc \\
\hline
\end{tabular}

\section{List of items used in study 3}

\section{Pseudowords used for reading aloud and spelling tasks}

Simple grapheme pseudowords: lople, mirpe, sinope, tanepi

Complex grapheme pseudowords: sulche, moube, turche, loumi

\section{Pseudowords used in the rhyme and alliteration tasks}

Rhyme task (C $\underline{\text { VC pseudowords) }})^{\mathrm{a}}$

bir/kir, tal/gor, guk/puk, jor/dik, dour/vour, gur/jik, mour/dol, full/dul, dal/fal, sul/vor

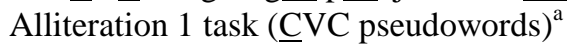

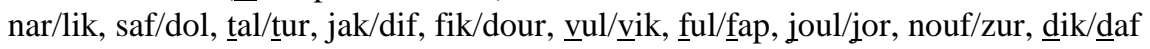

Alliteration 2 task ( $\underline{\mathrm{CCV}}$ pseudowords) ${ }^{\mathrm{a}}$

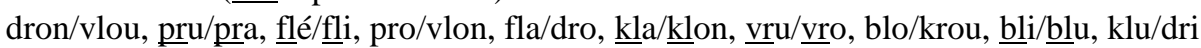

Onset + nucleus task (CVC pseudowords) ${ }^{\mathrm{a}}$

kil//kir, gal/gat, rél//rék, vour/kaf, kif/jok, doul/douk, gol/gor, gak/nur, dour/saf, dal/gok

a. Shared elements (rhyme, alliteration...) are underlined

\section{Pseudowords used in the syllable and phoneme deletion tasks}

First syllable deletion (CVCV): mouti, mida, jobi, buja, lanan, linza, fuji, lokin, ninco, boupi

First phoneme deletion (CV): nan, zon, ja, bi, chon, kin, zu, no, ji, da 